\title{
Efficacy and safety of sugammadex in patients undergoing renal transplantation
}

\author{
Yasumasa Ono, Yoshihito Fujita* (D), Takahiro Kajiura, Hazuki Okawa, Juntaro Nakashima, Hideo Isobe
}

and Yoshihiro Fujiwara

\begin{abstract}
Background: Sugammadex reverses rocuronium by encapsulating it, creating a stable complex that is mainly excreted by the kidneys. Nonetheless, in view of exposure to sugammadex during renal transplantation, current safety data are insufficient. We retrospectively investigated the safety and efficacy of sugammadex in the immediate perioperative period and over long-term follow-up.

Case presentation: We studied 99 consecutive patients who underwent living renal transplantation. We investigated the efficacy of sugammadex and its perioperative complications in the first 48-72 $\mathrm{h}$ in the surgical intensive care unit and in the follow-up for 6 months.

Before transplantation, 53 patients required hemodialysis. The median serum creatinine concentration was $5.6 \mathrm{mg} / \mathrm{dl}$, and blood urea nitrogen (BUN) was $30 \mathrm{mg} / \mathrm{dl}$. During surgery, the median rocuronium and sugammadex dose was $160 \mathrm{mg}$ (interquartile range 130-185 mg) and $200 \mathrm{mg}$ (200-200 mg), respectively. After transplantation, the median serum creatinine concentration was $2.4 \mathrm{mg} / \mathrm{dl}$ at postoperative day 1, and BUN was $21 \mathrm{mg} / \mathrm{dl}$, respectively. No adverse events were recorded during the observation period.
\end{abstract}

Conclusion: We investigated whether 99 consecutive patients undergoing renal transplantation may benefit from the use of sugammadex. There were no adverse events. We concluded that, in our observational period, sugammadex was efficacious and safe in patients who underwent renal transplantation.

Keywords: Rocuronium, Sugammadex, Renal transplantation, Safety, Efficacy

\section{Background}

Sugammadex reverses rocuronium by encapsulating it, creating a stable complex that is mainly excreted by the kidneys. Although sugammadex clearance is reduced in renal impairment [1], case reports have described the safe use of rocuronium and sugammadex in renal transplantation [2]. Nonetheless, in view of exposure to sugammadex during renal transplantation, current safety data are insufficient. We retrospectively investigated the safety and efficacy of sugammadex in the immediate perioperative period and over long-term follow-up.

\section{Case presentation}

We studied 99 consecutive patients who were diagnosed with severe renal failure and underwent living renal

\footnotetext{
* Correspondence: fujita.yoshihito.823@mail.aichi-med-u.ac.jp

Department of Anesthesiology, Aichi Medical University School of Medicine,

1-1 Yazako Karimata, Nagakute, Aichi 480-1195, Japan
}

transplantation under general anesthesia at our institution between March 2011 and June 2016 (Tables 1 and 2). Ethical approval for this study (2016-H281) was provided by the Ethical Committee of Aichi Medical University, Nagakute, Japan (Chairperson Prof M. Hanyuuda) on 19 December 2016. Obtaining written informed consent from each individual was waived from the Ethical Committee because of its retrospective manner and publication of its information on the website of the hospital. We investigated the efficacy of sugammadex and recorded perioperative complications in the first $48-72 \mathrm{~h}$ in the surgical intensive care unit. We followed up all patients for longer than 6 months.

In all patients, anesthesia was maintained with either sevoflurane or desflurane and intravenous opioids. Intraoperative anesthetic management was performed by the attending anesthesiologist who had more than 5 years of experience. Generally, propofol $(1-1.5 \mathrm{mg} / \mathrm{kg}$ ) and rocuronium $(0.6-0.9 \mathrm{mg} / \mathrm{kg})$ were used for tracheal intubation. 
Table 1 Patient characteristics and renal function

\begin{tabular}{ll}
\hline Age (years) & $53(43-61)$ \\
Height $(\mathrm{m})$ & $166(158-170)$ \\
Weight $(\mathrm{kg})$ & $59(51-69.5)$ \\
$\mathrm{BMI}\left(\mathrm{kg} / \mathrm{m}^{2}\right)$ & $22(20-24)$ \\
Sex $(\mathrm{F} / \mathrm{M})$ & $63(63.6 \%), 36(36.4 \%)$ \\
Creatinine (mg/dl) & $5.6(4.5-7.5)$ \\
BUN (mg/dl) & $30(24.5-34.5)$ \\
eGFR (ml/min/1.73mm $\left.{ }^{3}\right)$ & $8(6-11)$ \\
Dialysis episode (number) & \\
$\quad$ None or $<1$ month & $53(53.5 \%)$ \\
$\quad<12$ months & $19(19.2 \%)$ \\
$\quad \geqq 12$ months & $27(27.3 \%)$ \\
Anesthesia (min) & $425(382-459.5)$ \\
Surgery (min) & $317(290-358)$ \\
Rocuronium dose (mg) & $160(130-185)$ \\
Sugammadex dose (mg) & $200(200-200)$ \\
\hline
\end{tabular}

Values are median (interquartile range) or number (\%) $B M I$ body mass index, $B U N$ blood urea nitrogen, eGFR estimated glomerular filtration rate

Adjustment of rocuronium was determined by the attending anesthesiologist with monitoring by acceleromyography (TOF-Watch SX; Organon Ireland Ltd., a division of MSD, Dublin, Ireland). Train-of-four (TOF) ratio was kept to count 0 or 1 . Standard monitoring was performed, and core rectal temperature was maintained above $36.0{ }^{\circ} \mathrm{C}$ throughout the surgery with a forced-air warmer blanket. For immunosuppression, $20 \mathrm{mg}$ basiliximab at the start of surgery and $500 \mathrm{mg}$ methylprednisolone before anastomosis of the renal artery and vein were administered. After surgery, the attending anesthesiologist determined the adequacy of neuromuscular transmission by clinical signs, a bucking reaction against the endotracheal tube, spontaneous breathing, and movement of extremities in response to commands. A total of $2-4 \mathrm{mg} / \mathrm{kg}$ sugammadex was administered, and the tracheal tube was extubated with confirmed clinical signs and a TOF ratio > 0.9 . The patients were transferred to the surgical intensive care unit (SICU) and had preoperative care until day 2 or 3. In the SICU, standard monitoring and a daily blood test were performed, and oral immunosuppression drugs were administered.

The primary safety variable was the occurrence of postoperative complications related to recurarization, such as upper airway obstruction requiring mechanical intervention, hypoxemia $(\mathrm{SpO} 2<90)$ with $10 \mathrm{l} / \mathrm{min}$ supplemental oxygen administration with mask, need for tracheal reintubation, and muscular weakness until hospital discharge, and more than a 6-month follow-up period. We investigated these signs and symptoms described above from medical records during the stay in the SICU and in-hospital. We interviewed the attendant doctor for ambulatory care and checked medical records after hospital discharge. The secondary variable was renal function after surgery.

The median age, height, and weight of the cohort were 53 years, $1.66 \mathrm{~m}$, and $59.0 \mathrm{~kg}$, respectively. There were $63(36.4 \%)$ men. Fifty-three patients required dialysis for $<1$ month (53.5\%), 19 for $<1$ year (19.2\%), and 27 for $>1$ year $(27.3 \%)$. The median serum creatinine concentration before transplantation was $5.6 \mathrm{mg} / \mathrm{dl}$, blood urea nitrogen $(\mathrm{BUN})$ was $30 \mathrm{mg} / \mathrm{dl}$, and the estimated glomerular filtration rate (eGFR) was $8 \mathrm{ml} / \mathrm{min} / 1.73 \mathrm{~mm}^{2}$. The median duration of anesthesia and surgery was 425 and $317 \mathrm{~min}$, respectively. The median rocuronium dose was $160 \mathrm{mg}$ (interquartile range $130-185 \mathrm{mg}$ ). Three (3.0\%) patients were administered sugammadex $<200 \mathrm{mg}$, one (1\%) was administered $250 \mathrm{mg}$, one (1\%) was administered $280 \mathrm{mg}$, two (2.0\%) were administered $300 \mathrm{mg}$, two (2.0\%) were administered $400 \mathrm{mg}$, and 89 (89.9\%) were administered $200 \mathrm{mg}$. One patient was not administered sugammadex because the patient was not extubated at the operation room owing to deterioration of oxygenation. This patient had moderate renal insufficiency and congestive heart failure. At postoperative day 2, he was successfully extubated without sugammadex.

The median serum creatinine concentration after transplantation was $2.4 \mathrm{mg} / \mathrm{dl}$ at postoperative day 1 and

Table 2 Renal function and complication after surgery

\begin{tabular}{|c|c|c|c|c|c|}
\hline & Day 1 & Day 3 & Day 5 & Discharge & $\geqq 6$ months \\
\hline \multicolumn{6}{|c|}{ Renal function after surgery } \\
\hline Creatinine & $2.4(1.75,3.45)$ & $1.3(0.9,1.6)$ & $1.2(1.0,1.5)$ & $1.2(1.0,1.6)$ & $1.4(1.1,1.6)$ \\
\hline BUN & $21(17,27)$ & $18(14,24)$ & $20(16,28)$ & $17(13.5,21)$ & $21(18,25)$ \\
\hline eGFR & $22(14.5,30.5)$ & $48(35.5,58)$ & $47(38.5,57.5)$ & $45(38,55.5)$ & $40(33,49)$ \\
\hline \multicolumn{6}{|c|}{ Complication with muscle relaxants } \\
\hline $72 \mathrm{~h}$ in ICU & 0 & & & & \\
\hline Following period & 0 & & & & \\
\hline
\end{tabular}

Values are median (interquartile range)

BUN blood urea nitrogen, eGFR estimated glomerular filtration rate 
$1.4 \mathrm{mg} / \mathrm{dl}$ at postoperative day 3 , BUN was 21 and $18 \mathrm{mg} / \mathrm{dl}$, and eGFR was 47 and $48 \mathrm{ml} / \mathrm{min} / 1.73 \mathrm{~mm}^{2}$, respectively. No adverse events were recorded during the observation period.

\section{Discussion}

We investigated whether 99 consecutive patients undergoing renal transplantation may benefit from the use of sugammadex over a long period. Efficacy of rocuronium and sugammadex, that is muscle reluctant and its reversal, was obtained in our patients. There were no adverse events. We concluded that, in our observational period, sugammadex was efficacious and safe in patients who underwent renal transplantation.

In patients with end-stage renal failure, $4 \mathrm{mg} / \mathrm{kg}$ of sugammadex reverses deep neuromuscular blockade (NMB) [1, 3]. In our observational period, two patients needed another dose of sugammadex (total dose 5.17 and $5.19 \mathrm{mg} / \mathrm{kg}$ ) after the first 200-mg sugammadex administration for complete recovery. These patients did not obtain complete recovery and their first sugammadex administrations did not reach $4 \mathrm{mg} / \mathrm{kg}$. No patients required additional sugammadex administration at a total amount of more than $4 \mathrm{mg} / \mathrm{kg}$. Therefore, our data agree with the findings of $4 \mathrm{mg} / \mathrm{kg}$ sugammadex for obtaining recovery from deep $\mathrm{NMB}$ with renal impairment $[1,3]$.

In our study, no adverse events were recorded after obtaining complete recovery. Fourteen (14.3\%) patients had severe renal impairment $(\mathrm{eGFR}<30)$ at postoperative day 5 . However, there were no signs of recurarization. A sugammadex-rocuronium complex might exist in equilibrium in a low dissociation constant because of strong binding [4]. Additionally, in severe renal failure, the clearance of sugammadex is reduced by 17 -fold and the elimination half-time is increased by 15 -fold $[5,6]$. If recurarization had happened, we thought that the sugammadex-rocuronium complex might detach for a longer period due to limited excretion. In our setting after renal transplantation, the sugammadex-rocuronium complex might excrete without detachment. In renal transplant patients, the sugammadex-rocuronium complex might remain stable for a long time.

In most of our cases the patients were administered $200 \mathrm{mg}$ of sugammadex at first time without titrating recovery and patients almost obtained enough recovery. Because more amounts of sugammadex could obtain stronger recovery, the many attending anesthesiologists might use full amount of one vial of sugammadex, $200 \mathrm{mg}$. However, the main complication of sugammadex is the anaphylactic reaction and is estimated at 29 per $1,000,000$ of the population [7]. In our setting, no symptoms associated with allergic reaction were observed. We should pay attention to the titrating amount of sugammadex.
The present findings have limitations. We consider that our study of 98 successfully treated cases had enough power to show the long-term efficacy and safety of rocuronium and sugammadex in patients undergoing renal transplantation because of no complications (0\%, $95 \%$ confidence interval 0-3.0\%). However, our study was not a controlled, pharmacokinetic, and pharmacodynamic study [8].

\section{Conclusion}

We investigated whether 99 consecutive patients undergoing renal transplantation may benefit from the use of sugammadex. There were no adverse events. In our observational period, sugammadex appears to be safe and efficacious in patients undergoing renal transplantation.

\section{Abbreviations}

BUN: Blood urea nitrogen; eGFR: Estimated glomerular filtration rate; NMB: Neuromuscular blockade; SICU: Surgical intensive care unit; TOF: Train-of-four

\section{Funding}

Support was provided solely from institutional and departmental sources.

Availability of data and materials

Please contact the author for data requests.

\section{Authors' contributions}

$\mathrm{YO}, \mathrm{YF}, \mathrm{TK}, \mathrm{HO}, \mathrm{JN}$, and YF participated in the design of the study and performed statistical analysis. YF drafted the manuscript. YO, TK, HO, JN, and $\mathrm{HI}$ acquired data of the patients and analyzed data. YF conceived of the study, participated in the design and coordination, and helped to draft the manuscript. All authors read and approved the final manuscript.

\section{Ethics approval and consent to participate}

Ethical approval for this study $(2016-\mathrm{H} 281)$ was provided by the Ethical Committee of Aichi Medical University, Nagakute, Japan (Chairperson Prof M. Hanyuuda) on 19 December 2016. This study was observational. We did not publish the personal data that could identify the patients, for example, name and medical history. In addition, we provide this study information for the participants on the WEB, and if the participant would like to get rid of his or her data in this study, he or she has the right to do so. Therefore, the Ethical Committee waived to obtain the written consent.

\section{Consent for publication}

Not applicable.

\section{Competing interests}

The authors declare that they have no competing interests.

\section{Publisher's Note}

Springer Nature remains neutral with regard to jurisdictional claims in published maps and institutional affiliations.

Received: 26 May 2018 Accepted: 16 July 2018

Published online: 25 July 2018

\section{References}

1. Panhuizen IF, Gold SJ, Buerkle C, Snoeck MM, Harper NJ, Kaspers MJ, van den Heuvel MW, Hollmann MW. Efficacy, safety and pharmacokinetics of sugammadex 4 mg kg-1 for reversal of deep neuromuscular blockade in patients with severe renal impairment. Br J Anaesth. 2015;114:777-84.

2. Carlos RV, Torres ML, de Boer HD. The use of rocuronium and sugammadex in paediatric renal transplantation: two case reports. Eur J Anaesthesiol. 2016;33:383-6. 
3. De Souza CM, Tardelli MA, Tedesco H, Garcia NN, Caparros MP, AlvarezGomez JA, de Oliveira Junior IS. Efficacy and safety of sugammadex in the reversal of deep neuromuscular blockade induced by rocuronium in patients with end-stage renal disease: a comparative prospective clinical trial. Eur J Anaesthesiol. 2015;32:681-6.

4. Naguib M. Sugammadex: another milestone in clinical neuromuscular pharmacology. Anesth Analg. 2007;104:575-81.

5. Staals LM, Snoeck MM, Driessen JJ, Flockton EA, Heeringa M, Hunter JM. Multicentre, parallel-group, comparative trial evaluating the efficacy and safety of sugammadex in patients with end-stage renal failure or normal renal function. Br J Anaesth. 2008;101:492-7.

6. Staals LM, Snoeck MM, Driessen JJ, van Hamersvelt HW, Flockton EA, van den Heuvel MW, Hunter JM. Reduced clearance of rocuronium and sugammadex in patients with severe to end-stage renal failure: a pharmacokinetic study. Br J Anaesth. 2010;104:31-9.

7. Takazawa T, Tomita Y, Yoshida N, Tomioka A, Horiuchi T, Nagata C, Orihara M, Yamada MH, Saito S. Three suspected cases of sugammadex-induced anaphylactic shock. BMC Anesthesiol. 2014;14:92.

8. Unterbuchner C. Use of rocuronium and sugammadex in renal transplantation: problems that must be considered. Eur J Anaesthesiol. 2016;33:690-1.

\section{Submit your manuscript to a SpringerOpen ${ }^{\circ}$ journal and benefit from:}

- Convenient online submission

- Rigorous peer review

- Open access: articles freely available online

High visibility within the field

- Retaining the copyright to your article

Submit your next manuscript at $\boldsymbol{\nabla}$ springeropen.com 